\title{
Desenvolvimento de Marcadores Moleculares para Análogos a Genes de Resistência em Arachis spp. Silvestres
}

\author{
Patrícia M. Guimarães ${ }^{1}$, Ana Carolina F.V. José ${ }^{1,2}$, Karina Proite ${ }^{1,3}$, David J. Bertioli ${ }^{2}$ \\ \& Soraya C. M. Leal-Bertioli ${ }^{1}$
}

${ }^{1}$ EMBRAPA Recursos Genéticos e Biotecnologia, Cx. Postal 02372, CEP 70770-900, Brasília, DF; e-mail: messenbe@ cenargen.embrapa.br; ${ }^{2}$ Universidade Católica de Brasília, Campus II, SGAN 916, CEP 70790-160, Brasília, DF; ${ }^{3}$ Universidade de Brasília, Cx. Postal 70910, Brasília, DF

(Aceito para Publicação em 06/09/2005)

Corresponding author: Patrícia Messenberg Guimarães

GUIMARÃES, P.M., JOSÉ, A.C.F.V., PROITE, K., BERTIOLI, D.J. \& LEAL-BERTIOLI, S.C.M. Desenvolvimento de marcadores moleculares para análogos a genes de resistência em Arachis spp. silvestre. Fitopatologia Brasileira 30:663667. 2005.

\section{RESUMO}

O maior grupo de genes de resistência de plantas já clonados codifica para proteínas com um sítio de ligação a nucleotídios (NBS) na região N-terminal, e um domínio rico em repetições de leucina (LRR) na região C-terminal. Genes desta classe conferem resistência a diversos patógenos incluindo vírus, bactérias, fungos e nematóides. Para diferentes espécies do gênero Arachis, primers de "polymerase chain reaction" (PCR) degenerados foram construídos para a região NBS, e o produto de tradução putativo indicou similaridade com proteínas de resistência conhecidas sendo denominados análogos a genes de resistência (RGAs). Doze destes RGAs foram utilizados para o desenvolvimento de marcadores moleculares baseados em seus padrões de hibridização com DNA de Arachis spp. digerido com enzimas de restrição. Inicialmente, avaliou-se o polimorfismo de cada RGA como sonda nos parentais de uma população de mapeamento, contrastantes quanto à resistência as manchas foliares e nematóides das galhas, e no híbrido $\mathrm{F}_{1}$. Os RGAs, mesmo isolados de espécies diferentes do gênero Arachis apresentaram homologia com o DNA das espécies testadas, além de apresentarem múltiplas cópias e alto polimorfismo na progênie $\mathrm{F}_{2}$. Todas estas características tornam estes RGAs marcadores moleculares altamente informativos, sendo que alguns apresentaram segregação em "clusters" na $\mathrm{F}_{2}$, indicando que seus locos estão ligados. Estes marcadores serão incluídos em um mapa genético de Arachis spp., o que será de grande utilidade para os programas de melhoramento do amendoim (Arachis hypogaea) cultivado.

Palavras-chave adicionais: amendoim, resistência, mapa genético.

\begin{abstract}
Development of molecular markers for resistance gene analogs in wild Arachis spp.

The majority of cloned plant pathogen resistance genes ( $\mathrm{R}$ genes) encode a putative nucleotide binding site (NBS) domain and a leucine-rich repeat (NBS-LRR genes). Genes of this NBS-LRR class confer resistance to diverse pathogens such as viruses, bacteria, fungi, nematodes and aphids. The conserved NBS domain was used to generate resistance gene analogues (RGAs) fragments by polymerase chain reaction (PCR) using degenerated primers in different Arachis species. Twelve of these RGAs were used to develop molecular markers based on their patterns of hybridisation to restricted Arachis spp. DNA. An initial step was the evaluation of the polymorphism generated by each RGA in genomic fragments of contrasting parents of a mapping population that segregates for resistance to leaf spot and nematodes, and of the $\mathrm{F}_{1}$ hybrid. The RGAs isolated from different Arachis species showed high homology to the DNA of the parents and hybrid, multiple copies in the genome and high polymorphism in the $\mathrm{F}_{2}$ generation. Therefore, they were considered highly informative markers, with some segregating in clusters in the $\mathrm{F}_{2}$. These RGAs will be included in the Arachis genetic map, which will be of paramount importance for the Arachis spp. breeding programs.
\end{abstract}

Additional keywords: peanut, resistance, genetic mapping.

O amendoim cultivado (Arachis hypogaea L.) cobre uma área de 25,5 milhões de ha em ambos os hemisférios com uma produção global de 35 milhões de ton/ano (FAO, 2001). É uma das cinco principais culturas oleaginosas crescidas em todo mundo, sendo uma importante fonte de proteína vegetal comestível. O gênero Arachis tem seu centro de origem na América do Sul, mas a maior produção da cultura encontra-se na Ásia $(66,8 \%)$ e África $(24,6 \%)$.

No Brasil, o amendoim é produzido principalmente em regiões semi-áridas, por pequenos produtores que são afetados principalmente pela seca e por fungos causadores de manchas foliares, tais como Cercospora arachidicola Hori (Mancha parda) e Cerscosporidium personatum (Berk. \& Curt.) Deighton (Mancha preta), que são responsáveis por perdas de até $50 \%$ em cultivares não resistentes em todo o mundo (Meena et al., 2002). Embora estejam disponíveis acessos de A. hypogaea com diferentes níveis de resistência, o melhoramento das cultivares é dificultado devido à 
resistência ser determinada, em geral, por vários genes e apresentar baixo nível de polimorfismo genético. Por outro lado, as espécies silvestres de Arachis são geneticamente bem diversas e ricas em fontes de resistência a várias doenças (Galgaro et al., 1997). Bioensaios conduzidos in vitro e em casa de vegetação identificaram fontes de resistência a fungos foliares, a ferrugem causada por Puccinia arachidis Speg. e a três espécies do nematóide das galhas, Meloidogyne arenaria (Neal) Chitwood, M. hapla Chitwood e M. javanica (Treub) Chitwood (Leal-Bertioli et al., 2004) em germoplasma de Arachis spp. silvestres.

O maior grupo de genes de resistência de plantas já clonados codifica para proteínas com um domínio de ligação a nucleotídios (NBS) na região N-terminal, e para uma região com repetições ricas em leucina (LRR) no C-terminal. Genes desta classe conferem resistência a diversos patógenos incluindo vírus, bactérias, fungos e nematóides (Rossi et $a l ., 1998)$. Enquanto a região LRR é muito variável, a região NBS apresenta "motivos conservados" (Kobe \& Deisenhofer, 1994). Para diversas espécies de plantas, foram desenhados diferentes conjuntos de primers de "polymerase chain reaction"PCR degenerados para a região NBS os quais foram utilizados na amplificação de seqüências genômicas. A análise das sequiências nucleotídicas amplificadas e do produto de tradução putativo das mesmas, indicou similaridade com genes de resistência conhecidos, sendo denominados análogos a genes de resistência (RGAsResistance Gene Analogs). Alguns destes RGAs estão geneticamente ligados a locos de genes de resistência ou parte dos mesmos ( Madsen et al., 2003).

No caso específico de Arachis spp., esta técnica foi utilizada para se isolar um total de 78 RGAs do amendoim cultivado e de parentes silvestres (A. cardenasii Krapov. \& W.C. Gregory, A. duranensis Krapov. \& W.C. Gregory, A. stenosperma Krapov. \& W.C. Gregory e A. simpsonii Krapov. \& W.C. Gregory) (Bertioli et al., 2003; Guimarães et al., 2003) já previamente descritos como fonte de resistência a diversas doenças. Para se relacionar estes RGAs com resistências específicas, é necessário transformá-los em marcadores moleculares e inseri-los no mapa genético de Arachis spp., cujos parentais contrastam para as resistências de interesse (Moretszohn et al., 2004). Uma das técnicas que possibilitam a análise da segregação destes RGAs para uma determinada característica é a de "Southern-blot", que permite detectar fragmentos de DNA específicos em amostras de composição complexa, possibilitando inclusive a estimativa do número de cópias daquela seqüência no genoma (Madsen et al., 2003).

O objetivo deste trabalho foi desenvolver marcadores moleculares do tipo RGA, através de "Southern-blot", visando sua aplicação na identificação de locos associados às resistências no mapa genético de Arachis spp. Inicialmente, avaliou-se o polimorfismo de cada RGA, utilizando-o como sonda no DNA dos parentais contrastantes (A. stenosperma V10309 (resistente) e A. duranensis K7988 (suscetível)) quanto à resistência as manchas foliares e ao nematóide das galhas e na planta $\mathrm{F}_{1}$ híbrida. Em seguida, as sondas selecionadas como polimórficas entre os parentais foram testadas em representantes da progênie $F_{2}$, visando a sua inclusão em mapa genético de Arachis spp. e sua posterior associação com genes de resistência.

Em trabalhos anteriores (Bertioli et al., 2003; Guimarães et al., 2003), classificou-se os RGAs isolados de diferentes espécies de Arachis silvestre em diferentes clades, de acordo com a similaridade de suas sequiências nucleotídicas. Um RGA de cada uma destas clades foi escolhido como sonda de forma a se ter amostras representativas de todas as seqüências isoladas. Os clones utilizados neste trabalho estão listados na Tabela 1. As sondas consistiam de produtos de PCR, a partir dos plasmídeos contendo estes RGAs, marcados com $\alpha-\mathrm{P}^{32}$, segundo protocolo do fabricante (Ready to Go-Amersham). Para a seleção de RGAs polimórficos entre os parentais, DNA total de V10309, K7988 e da planta híbrida $F_{1}$ foi extraído utilizando o método de CTAB, seguido de digestão com as enzimas EcoRI e HindIII. Os produtos da digestão foram separados em gel de agarose $0,8 \%$ e transferidos para membrana de nylon Hybond N (Amersham, Pharmacia) por capilaridade em SSC, com o auxílio de um transferidor a vácuo (BioRad). Para a análise da progênie $\mathrm{F}_{2}$, utilizou-se DNA de 20 plantas que apresentaram diversos graus de susceptibilidade a $C$. personatum para a confecção das membranas. As hibridizações foram realizadas segundo o protocolo da membrana Hybond N (Amersham, Pharmacia).

Dos doze clones de RGAs de Arachis spp. utilizados como sondas, foi possível observar alguns que hibridizaram com apenas um fragmento de restrição e outros que hibridizaram com múltiplos fragmentos de cada parental (Tabela 1), sugerindo a existência de um locos complexo ou mesmo de uma família multigênica, o que é compatível com a organização de genes de resistência (Michelmore \& Mayers, 1998). No total, foram encontradas 33 bandas diferenciadoras para as duas enzimas testadas, que constituem marcadores moleculares gênicos em potencial, a serem incluídos no mapa de Arachis spp. (Tabela 1). Como exemplo, o padrão de hibridização das sondas RGA S1_A_36 (A) e S1_A_37 (B) onde três e 11 bandas polimórficas foram identificadas respectivamente (Figura 1). Como já descrito para outras espécies de plantas (Michelmore \& Meyers 1998), observou-se um alto nível de polimorfismo gerados pelos RGAs testados em DNA genomico de Arachis spp. Além disso, foi possível observar que o padrão de hibridização destes RGAs foi distinto para cada sonda testada, confirmando a separação destes RGAs em clades obtida através da análise de suas seqüências por BLASTN e CLUSTAW (Bertioli et al., 2003). Observou-se também, que como estas sequiências contém longos trechos conservados, independente da espécie de Arachis da qual foi originada, todas as sondas apresentaram homologia com o DNA dos parentais. Isto amplia a possibilidade de aplicação destas mesmas sondas em populações segregantes para outras resistências derivadas de outros cruzamentos. 
Desenvolvimento de marcadores moleculares para análogos a genes...

TABELA 1 - Tipo de polimorfismo e origem dos clones de Arachis spp. utilizados como sondas em análises de "Southern blot"

\begin{tabular}{|c|c|c|c|c|}
\hline \multirow{3}{*}{$\begin{array}{l}\text { Clone } \\
\text { S4C8_AX_402 }\end{array}$} & \multirow{3}{*}{$\frac{\text { Clade }}{\mathrm{N}}$} & \multirow{3}{*}{$\begin{array}{l}\text { Espécie(s) de origem } \\
\text { Arachis stenosperma } \\
\text { A. cardenasii }\end{array}$} & \multicolumn{2}{|c|}{ Número de bandas polimórficas/enzima } \\
\hline & & & 1 dominante V10309 & $E c o R I$ \\
\hline & & & 1 dominante K7988 & Hind III \\
\hline C8_XY_340 & A & A. cardenasii & 1 dominante K7988 & EcoR I \\
\hline \multirow[t]{2}{*}{ S4_A_164 } & $\mathrm{R}$ & A. stenosperma & 1 dominante V10309 & Hind III \\
\hline & & & 1 dominante V10309 & $E c o R I$ \\
\hline \multirow[t]{2}{*}{ S1_A_36 } & $\mathbf{M}$ & A. stenosperma & 1 dominante K 7988 & Hind III \\
\hline & & & 1 dominante V10309 & Hind III \\
\hline \multirow{2}{*}{ S1_A_37 } & \multirow{2}{*}{$\mathrm{O}$} & \multirow{2}{*}{ A. stenosperma } & 4 dominante V10309 & EcoR I \\
\hline & & & 7 dominante V10309 & Hind III \\
\hline C8_V_434 & $\mathrm{E}$ & A. cardenasii & 1 dominante K7988 & EcoRI \\
\hline T_A_ 44 & M & A. hypogaea & 1 dominante V10309 & Hind III \\
\hline S1_S2_A_152 & $\mathrm{A}$ & A. stenosperma & 2 V10309 & Hind III \\
\hline \multirow{2}{*}{ C8_Y_260 } & \multirow{2}{*}{$\mathrm{C}$} & \multirow{2}{*}{ A. hypogaea } & 2 dominante V10309 & EcoR I \\
\hline & & & 1 dominante K 7988 & EcoR I \\
\hline S5_A_375 & $\mathrm{O}$ & A. stenosperma & 1 dominante V10309 & Hind III \\
\hline S5_A_384 & $\mathrm{N}$ & A. stenosperma & 2 dominante K7988 & Hind III \\
\hline \multirow{2}{*}{ S5C8_AXY_370 } & \multirow{2}{*}{ Q } & A. stenosperma & 1 dominante K7988 & Hind III \\
\hline & & A. cardenasii & 1 dominante V10309 & EcoR I \\
\hline
\end{tabular}

Número total de marcadores produzidos

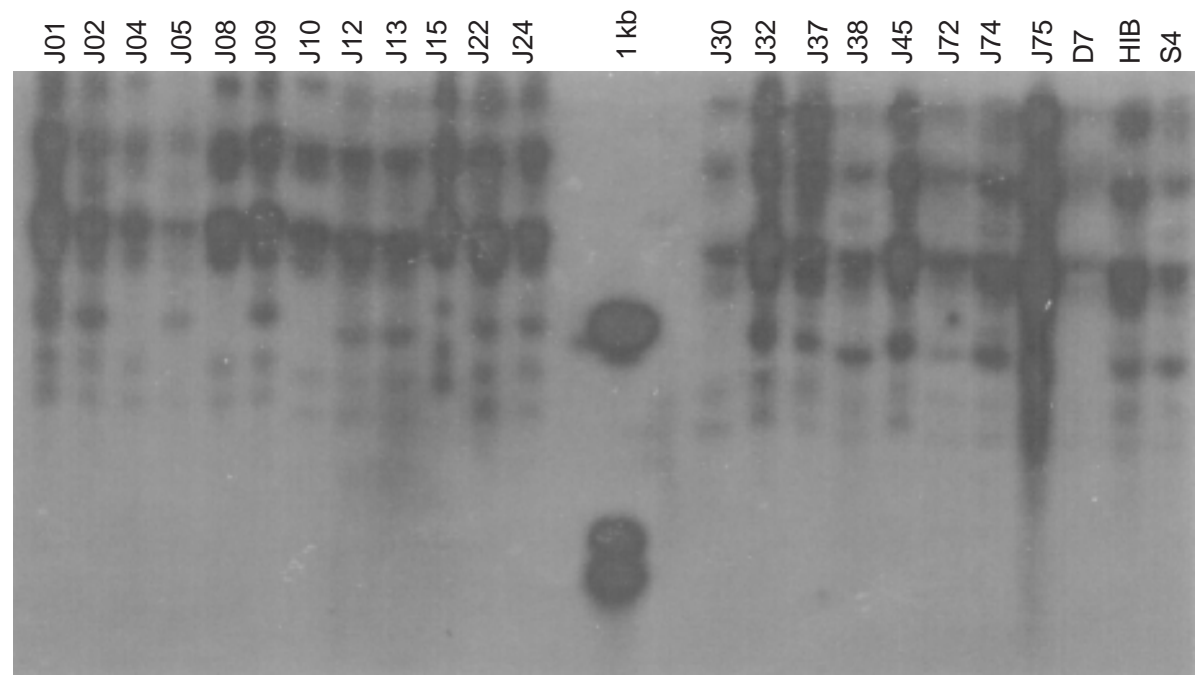

FIG. 1 - "Southern-Blot" genômico de parentais e híbrido de Arachis spp., digeridos com EcoRI e HindIII usando como sondas RGA S1_A_36 (A) e S1_A_37 (B). 1 e 5 - Arachis duranensis (K7988); 2 e 6 - Híbrido A. duranensis x A. stenosperma; 3 e 7 - Arachis stenosperma (V10309); 4 e 8 - Arachis stenosperma (SV2411) e 5 - 1 kb DNA Ladder.

Os RGAs identificados como polimórficos entre os parentais foram testados como marcadores do tipo "Restriction Fragment Lenght Polymorphism" (RFLP) em uma amostra de 20 plantas da população de mapeamento $\mathrm{F}_{2}$ e segregaram de maneira esperada: todos os marcadores que apresentam múltiplas bandas segregam juntos, sugerindo que estão geneticamente ligados ou estão no mesmo locos (Figura $2 \mathrm{~A} \mathrm{e} \mathrm{B}$ ). Isto foi demonstrado anteriormente para várias outras espécies como batata (Solanum tuberosum L.), arroz (Oryza sativa L.) e soja [Glycine max (L.) Merril]
(Wei et al., 2002), mas é a primeira vez que um estudo da segregação de RGAs é feito em Arachis spp. Baseados nestes dados, estas sequiências serão aplicadas a toda a população $\mathrm{F}_{2}$ visando incluir estes marcadores no mapa genético de Arachis spp. (Moretszohn et al., 2004).

Apesar de ainda não se saber se todos os genes do tipo NBS-LRR têm um papel direto na resistência a doenças, ou mesmo se são contribuintes para "Quantitative Trait Loci" (QTLs) associados a resistência, torna-se clara a importância de se obter informações sobre estas seqüências. Neste sentido, 
A

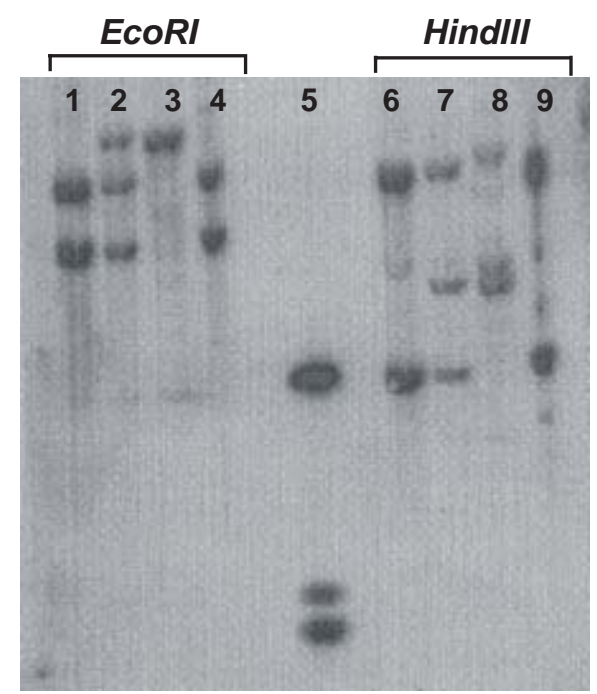

B

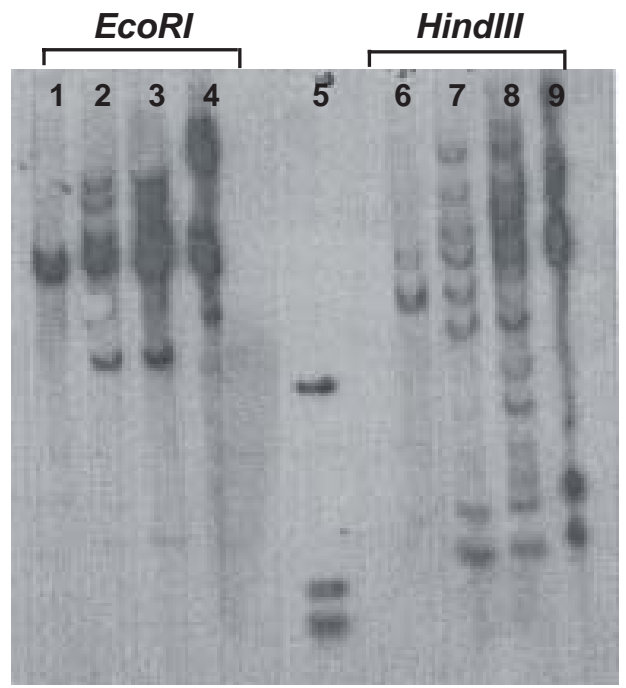

FIG. 2 - "Southern Blot" genômico de plantas representantes da progênie $\mathrm{F}_{2}$ (J01 a J75), D7 (Arachis duranensis), HIB (A. duranensis x A. sternosperma), S4 (A. stenosperma) usando como sonda RGA S1_S2_A132.

é de suma importância a inclusão destes RGAs no mapa genético de Arachis spp., o que possibilitará a associação destas seqüências a grupos de ligação contendo genes de resistência, ou mesmo identificar fontes de resistência ainda não caracterizadas. Além disso, estes RGAs estão sendo caracterizados como sondas em uma biblioteca genômica de A. stenosperma visando o isolamento das seqüências completa dos genes.

O desenvolvimento de mapas genéticos de parentes silvestres de amendoim, contendo marcadores gênicos do tipo RGA, auxiliará a seleção assistida de amendoim especialmente quanto à resistência a pragas e patógenos (uma vez que os genes de resistência estão normalmente agrupados no cromossomo), possibilitando também a piramidização de genes de resistência (Aarts et al., 1998). Além disso, vários trabalhos demonstraram que genes de resistência podem manter sua atividade quando transferidos para outras espécies (Hammond-Kosack et al., 1998), o que também abre a perspectiva de que, uma vez identificados os genes de resistência em Arachis spp., estes possam ser transferidos para outras espécies, especialmente leguminosas como soja, feijão (Phaseolus vulgaris L.) e ervilha (Pisum sativum L.), e que estes se mantenham ativos.

\section{LITERATURE CITED}

AARTS M.G, TE LINTEL, H. B., HOLUB, E.B., BEYNON, J.L., STIEKEMA, W.J. \& PEREIRA A. Identification of R-gene homologous DNA fragments genetically linked to disease resistance loci in Arabidopsis thaliana. Molecular Plant Microbe Interactions 4:251-258. 1998.

BERTIOLI D.J., LEAL-BERTIOLI, S.C., LION, M.B., SANTOS, V.L., PAPPAS, G. JR., CANNON, S.B. \& GUIMARÃES, P.M. A large scale analysis of resistance gene homologues in Arachis. Molecular Genetics and Genomics 270:34-45. 2003.
FAO. FAO Production Year Book 55:118-119. 2001.

GALGARO, L., LOPES, C.R., GIMENES, M., VALLS, J.F.M. \& KOCHERT, G. Genetic variation between species of sections Extranervosae, Caulorrhizae, Heteranthae, and Triseminatae (genus Arachis) estimated by DNA polymorphism. Genome 41:445-454. 1997.

GUIMARÃES, P.M., LEAL-BERTIOLI, S.C.M., SEIJO, G., PARNISKE, M., STOUGARD, J. \& BERTIOLI, D. The identification of resistances to biotic stress in wild Arachis germplasm, and the development of tools for breeding by genetic mapping and comparative genomics. 7th International Congress of Plant Molecular Biology. 23-28 June, Barcelona. 2003 (Abstract)

HAMMOND-KOSACK, K.E., TANG, S., HARRISON, K. \& JONES, J.D. The tomato $C f-9$ disease resistance product $a v r 9$ gene functions in tobacco and potato to confer responsiveness to the fungal avirulence gene. Plant Cell 10:1251-1266. 1998.

KOBE, B. \& DEISENHOFER, J. The leucine-rich repeat: a versatile binding motif. TIBS 19: 425-430. 1994.

LEAL-BERTIOLI, S.C.M., GUIMARÃES, P.M., FÁVERO, A.P, MORETZSOHN, M.C., PROITE, K. \& BERTIOLI, D.J. Amendoim selvagem: uma fonte de resistência a pragas. Biotecnologia Ciência e Desenvolvimento. Dezembro 2004. Site: www.biotecnologia.com.br. 2004.

MADSEN, L.H., COLLINS, N.C., RAKWALSKA, M., BACKES, G., SANDAL, N., KRUSELL, L., JENSEN, J., WATERMAN, E.H., JAHOOR, A., AYLIFFE, M., PRYOR, A.J., LANGRIDGE, P., SCHULZE-LEFERT, P. \& STOUGAARD, J. Barley disease resistance gene analogs of the NBS-LRR class: identification and mapping. Molecular Genetics and Genomics 269:150-161. 2003.

MAGO, R., NAIR, S. \& MOHAN, M. Resistance gene analogues from rice: cloning, sequencing and mapping. Theoretical and Applied Genetics 99:50-57. 1999.

MEENA, B., RADHAJEYALAKSHMI, R., MARIMUTHU, T., VIDHYASEKARAN, P. \& VELAZHAHAN, R. Biological control of groundnut late leaf spot and rust by seed and foliar applications 
of a power formulation of Pseudomonas fluorescens. Biocontrol Science and Technology 12:195-204. 2002.

MICHELMORE R.W. \& MEYERS B.C. Clusters of resistance genes in plants evolve by divergent selection and a birth-anddeath process. Genome Research 11:1113-30. 1998.

MORETSZOHN, M.C., LEOI, L., PROITE, K., OLIVEIRA, R.F.T.M., GUIMARÃES, P.M., LEAL-BERTIOLI, S.C.M. \& BERTIOLI, D.J. Desenvolvimento e mapeamento de marcadores microssatélites em Arachis. In: Congresso Brasileiro de Genética
50, CD-ROM. 2004. p.50.

ROSSI, M. GOGGIN, F.L., MILLIGAN, S.B., KALOSHIAN, I., ULLMAN, D.E. \& WILLIAMSON, V.M. The nematode resistance gene $M i$ of tomato confers resistance against the potato aphid. Proceedings of the National Academy of Sciences U.S.A. 95: 97509754. 1998.

WEI, F., WING, R.A. \& WISE, R.P. Genome dynamics and evolution of the Mla (Powdery Mildew) resistance locus in barley. Plant Cell 14:1903-1917. 2002. 